\title{
Influence of Operation Parameters on Metal Deposition in Bright Nickel-plating Process
}

\author{
O. Sadiku-Agboola, ${ }^{1,{ }^{*}}$ E.R. Sadiku, ${ }^{2}$ O.I. Ojo, ${ }^{1}$ O.L. Akanji, ${ }^{1}$ O.F. Biotidara ${ }^{2}$ \\ ${ }^{1}$ Department of Chemical Engineering, Faculty of Engineering and the Built \\ Environment, Tshwane University of Technology, Pretoria, South Africa. \\ ${ }^{2}$ Department of Mechanical Engineering, Faculty of Engineering and the Built \\ Environment, Tshwane University of Technology, Pretoria, South Africa.
}

Received 6 October 2010; accepted 27 March 2011

\begin{abstract}
Bright nickel deposits were electrolytically applied on steel in the nickel Watts bath. The effect of some operational parameters on metal deposition in bright nickel plating was investigated. The investigation indicated that the weight of bright nickel deposited on metal during the process of electroplating was affected by plating temperature, voltage, current density, plating bath $\mathrm{pH}$ and plating time. The study established that the deposition of best bright nickel was obtained at a plating temperature of $56{ }^{\circ} \mathrm{C}$, current density of $6 \mathrm{~A} / \mathrm{dm}^{2}$ and plating time of 18 minutes. Brightener is used in applications requiring outstanding appearance with minimum thickness of applied nickel plating. It can also be used for heavy deposit applications because it exhibits unparalleled ductility and low stress. Brightener was used in this study to determine the best nickel plating in the process. Boric acid was added for fixing the bath $\mathrm{pH}$. The compositions of the brightener and nickel solution used are included in the text.
\end{abstract}

Keywords: operational parameters, current density distribution, voltage, brightener and nickel deposit.

\section{Introduction}

Nickel is one of the most important metals applied by electro-deposition. The plate is used mainly as a bright coating underneath a much thinner chromium electroplate to provide a highly bright, shining and corrosion-protective finish for articles of steel, brass, zinc die castings, chemically metalized plastics, and, to a much smaller extent, for coatings on aluminium and magnesium alloys. The protection of the underlying metal depends primarily on the nickel plate. To some extent, and only for mild exposures, thin gold or brass electroplate with a

\footnotetext{
* Corresponding author. E-mail address: funmi2406@gmail.com
} 
clear lacquer finish is used as a decorative coating on thin bright nickel deposits. Nickel coatings alone are also used industrially to afford corrosion protection to prevent contamination of a product. Because of the advantageous mechanical properties, nickel electrodeposits are used for electroforming of printing plates: phonographs record stumpers, foil, tubes, screens, and many other articles.

Nickel plating is the electrolytic deposition of a layer of nickel on a substrate. The process involves the dissolution of one electrode (the anode) and the deposition of metallic nickel on the other electrode (the cathode). Direct current is applied between the anode (positive) and the cathode (negative). The aqueous solution of the nickel salts gives the conductivity between the electrodes. The length of time that the substrate is immersed in the electrolyte is the major factor in determining the thickness of the resulting deposit. The thermal, electrical and chemical characteristics of the electrolyte bath also influence the deposition process. The current flow distribution in the electrolyte surrounding the workpiece determines the distribution of the deposit on the workpiece. It is known that the workpiece rejection rate due to coating thickness problems is frequently above $5 \%$ in usual production. The rework of the rejected workpieces may involve costly stripping and replating [1]. One of the topical directions in the upgrading of nickel plating processes is the development of electrolytes that ensure sufficient intensity of the electrodeposition at reduced concentrations of precursor salts. This is important for decreasing the amount of toxic nickel (II) salts in electroplating sewage and for reducing the nickel plating cost (saving anodes and nickel salts) [2].

Nickel and nickel alloy coatings are commonly deposited by electroplating (the most commercially important process), electroless plating, thermal spraying, weld surfacing, and solid-state cladding techniques. For specialized application, nickel can also be deposited by selective plating, also known as brush plating, pulsed-current plating, and chemical vapour deposition (CVD). The first two of these processes are variations of the traditional tank or bath electroplating process. CVD involves the decomposition of nickel carbonyl at $180{ }^{\circ} \mathrm{C}$ [3]. Various types of plating processes are extensively employed in different industries, for the purposes of increasing the resistance to corrosion and also to impact improved decorative appearance to steel and to metals such as aluminium, zamak, and brass. Secondly, the most frequently used plating process is nickel plating (with zinc plating being most popular) [4]. Electrodeposited nickel has been used for various applications such as transport and service apparatus [5]. Nickel plating provides a distinct decorative appearance and corrosion resistance when applied on hard or soft metals. A usual electroplating line consists of different types of cleaning, many steps of rinsing, and a core operation of electroplating. The selection of electroplating bath depends mainly on the characteristics of the nickel deposit required. Nickel deposit from sulfamate bath has low stress and good mechanical properties [6], but this coating can be produced expensively and it is commercially undesirable for economic considerations.

Bright nickel plating is used extensively in automotive applications such as: plated wheels, bright trim, truck exhausts, bumpers and restorations. Nickel is 
used to achieve brigthness on hardware, such as hand tools. Most of the applications of bright nickel depend on the decorative appearance of nickel for corrosion protection and wearability. Its most important function is as an undercoating for chronium plating, helping finishers to achieve a smooth bright finish. Brigth nickel plating baths use combinations of organic agents such as aromatic sulfonic acids and brigthners to achieve bright nickel deposits. Nickel plated deposits using the first class of additive is mirror bright initially; however as nickel builds up, brightness diminishes. This first class of brighteners incorporates sulfur into the bright nickel, reducing corrosion resistance. Brighteners in the second class, have inorganic metal ions and organic compounds.

Researchers have done many investigations in the field of electroplating; however, there is need to upgrade nickel plating processes by developing electrolytes in order to ensure sufficient intensity of the electrodeposition at reduced concentrations of precursor salts. This is important for decreasing the amount of toxic nickel (II) salts in electroplating sewage and for reducing the nickel plating cost (saving anodes and nickel salts). Pavel et al. developed the state equation model of an electroplating line in the max algebra [7]. The state equation includes a control vector designed to ensure the control of the movements of the transporting system, to respect constraints and to optimize the production. Karavaev et al. [8] used geometric parameters taken from experimental results at various concentrations of $\mathrm{ZnO}$ to formulate and solve the problem of optimization of the electroplating process. This was achieved by the nonuniformity criterion, which accounts for the changes in the concentration of electrolyte components on the polarization. Zhang [9] employed a simple method to determine the Young's moduli of electroplated Ni/Fe of thin films shaped into micro-cantiliver beams. Kukharenka et al. [10] presented the optimization results of the process flow which relates to the Ordyl P-50100 dry film negative photoresist having $20 \mu \mathrm{m}$ and $90 \mu \mathrm{m}$ thicknesses. They demonstrated that Ordyl P-50100 dry film resist is a promising photoresist for the realization of high thickness moulds for electroplating applications. Kaneko et al. [11] investigated the influence of additives on the filling process, via holes in damascene electroplating by using the Kinetic Monte Carlo method. Three kind of additives were included in the model in order to control the local surface growth rate. Partial least square (PLS) regression and classical least square (CLS) were used by Vidal et al. [12] to quantify both additives during the whole duration of electroplating nickel bath. It was found that PLS regression provided the best results. The influence of temperature on the electroplating efficiency of various metals from ionic liquids was studied by Lambert [13]. Ghanem et al. [14] investigated the numerical correlation of these parameters using the regression analysis to simulate the recovery of nickel from nickel spent catalyst leachate and developed the operating conditions (by having a knowledge of the recovery process), to predict the current efficiency. The purpose of the present work is to study the influence of operational parameters on bright nickel plating process. 


\section{Function of constituents: the Watt bath \\ Nickel sulfate}

Most of the nickel ion content is contributed by nickel sulfate. This salt is used because it is the least expensive salt of nickel with a stable anion that is not reduced at the cathode, oxidized at the anode or volatized. It is also highly soluble and readily available commercially. Nickel sulfamate solutions are widely used for electroforming because of the low internal stress of the deposits, high rate of deposition, and superior throwing power. The throwing power is the relationship between current distribution and uniformity of coating thickness, as influenced by geometric factors (the shape and relative positioning of the anode and cathode) and by the electrochemical characteristics of the solution (conductivity, cathode polarization and cathode efficiency). Throwing power is a measure of the extent to which a solution will produce deposits that are more uniform than those that would be produced in the absence of cathode polarization and cathode efficiency effects. The limiting cathode current density for sound nickel deposits is a function of nickel concentration in the cathode film, which in turn depends on the metal ion concentration of the bath itself. The large amount of nickel sulfate now used in Watts bath, not only raises the limiting cathode current density, but also lowers the resistivity, thus improving plate distribution.

\section{Chloride ion}

A principal function of the chloride ion is to improve anode dissolution by reducing polarization. It improves the cathode efficiency and also improves the electrical conductivity of the solution. A small amount of nickel chloride is usually added to nickel sulfamate solutions to minimize anode passivity, especially at high current densities.

\section{Boric acid}

This serves as a weak buffer in a nickel plating solution. Its main effect is that of controlling $\mathrm{pH}$ in the cathode film. In the absence of a buffer, a nickel deposit, at ordinary temperatures, tends to be hard, cracked and pitted. Boric acid is obtainable in a very pure and inexpensive form, it is non-volatile and stable, it produces whiter deposits, it is helpful in its smoothing action on the deposit. It is unique in its cooperative effect with levelling addition agents.

\section{Experimental procedure}

Nickel electrodeposition was performed in the nickel Watt bath, composed of 200-300 g/L of nickel sulfate $\left(\mathrm{NiSO}_{4}-6 \mathrm{H}_{2} \mathrm{O}\right), 50 \mathrm{~g} / \mathrm{L}$ of nickel chloride $\left(\mathrm{NiCl}_{2}\right.$ $\left.6 \mathrm{H}_{2} \mathrm{O}\right), 40 \mathrm{~g} / \mathrm{L}$ of boric acid $\left(\mathrm{H}_{3} \mathrm{BO}_{3}\right)$ and $0.1-1 \mathrm{~g} / \mathrm{L}$ brightener. Small amount of distilled water was added to the salts to make the plating solution. The solution $\mathrm{pH}$ ranges from 4 to 4.5 and it is used to explore the effect of the solution on the deposition behavior. The plating bath was thoroughly cleaned in order to remove solid particles and dirt. The steels were mechanically cleaned by grinding and polishing. Grinding was done using different grade of sandpapers and polishing followed grinding. Polishing was done so as to remove significant amount of 
metal and to smooth the surface in a preliminary stage. This prepares them for a more refined smoothing by buffing and also to improve their appearances. Chemical surface preparation followed the mechanical cleaning. The chemical surface preparation was done by subjecting the steels into alkaline/detergent solution in order to remove heavy soil, oil and grease. After alkaline cleaning, the steels were dipped into acid (hydrochloric acid) for 30 minutes so as to remove traces of oxide film on the surface. The electroplating was perfomed at different time, temperature and voltage with the anodes and cathodes connected to the positive and negative terminals of the direct current, respectively. Steady flow of air was applied at all times. The reactions of the electroplating bath are given below.

\section{Electrochemical reaction}

$$
\mathrm{M}^{\mathrm{n}+}+\mathrm{ne}^{-} \rightarrow \mathrm{M}
$$

The quantity of metal deposited at the cathode or dissolved at the anode, and any hydrogen evolved at the cathode is given by the reaction below

$$
2 \mathrm{H}_{2} \mathrm{O}+2 \mathrm{e}^{-} \rightarrow \mathrm{H}_{2}+2 \mathrm{OH}^{-}
$$

And oxygen at the anode is given by the reaction below

$$
2 \mathrm{H}_{2} \mathrm{O} \rightarrow \mathrm{O}_{2}+4 \mathrm{H}^{+}(\mathrm{aq})+4 \mathrm{e}^{-}
$$

As soon as the metal salt dissolved in water, it dissociated into electrically charged particles, positively charged metal ions (cations) and negative acid radicals (anions). When direct current passes through the metal salt solution between two conductive electrodes, the positive metal ions move towards the cathode and become discharged and deposited on the cathode.

Below is the reaction of nickel plating

$$
\mathrm{Ni}^{++}+2 \mathrm{e}^{-} \rightarrow \mathrm{Ni}
$$

\section{Rate of electrodeposition}

Faraday's law indicates that the weight of the metal deposited in an electrolytic process is proportional to the current, plating time and its chemical equivalent. Thus:

$$
W=\text { Ite }
$$

where $W$ is the weight (in grams) of metal deposited, $I$ is the current (A), $t$ is time (secs) and $e$ is the chemical equivalent. The product of current and time (It), is the quantity of electricity passed. For a given coulomb, the weight of an element discharged is proportional to its chemical equivalent. One Faraday $(F)$ deposites a gram-equivalent of an element of atomic weight, $A$. 
$F=$ Faraday (an electricity to deposit 1 gram equivalent of metal $=96500$ coloumb or 26.8 amphere - hour), $C=$ Coulomb, $n=$ valence of the element, $A=$ atomic weight. Thus:

$$
W=I t A / n F
$$

\section{Results and discussion}

Tables 1 and 2 give, respectively, the bath composition and the operating conditions of the bright nickel plating.

Table 1. Bath composition of the bright nickel plating.

\begin{tabular}{|c|c|}
\hline Components & Concentration \\
\hline Nickel sulfate & $200-300 \mathrm{~g} / \mathrm{L}$ \\
\hline Nickel chloride & $50 \mathrm{~g} / \mathrm{L}$ \\
\hline Boric acid & $40 \mathrm{~g} / \mathrm{L}$ \\
\hline $\mathrm{pH}$ & $4-4.5$ \\
\hline
\end{tabular}

Table 2. Bath operating conditions of the bright nickel plating.

\begin{tabular}{|c|c|}
\hline $\begin{array}{c}\text { Operating } \\
\text { parameters }\end{array}$ & Operating conditions \\
\hline Temperature & $42-56^{\circ} \mathrm{C}$ \\
\hline Deposition time & $18-27$ min \\
\hline Voltage & $2.2-3.5$ Volts \\
\hline Agitation & Air agitation \\
\hline Deposition condition & Bright plating \\
\hline
\end{tabular}

Fig. 1 shows the schematic representation of the electrolytic cell used for the electrodeposition of bright nickel together with the electric circuit and the bath composition with the operating conditions used for bright nickel plating. There is a good correlation between the temperature and current density, with a coefficient of fit, $\mathrm{R}^{2} \approx 94 \%$, as shown in Fig. 2, which indicates that the temperature increases as the current density increases. This was expected because higher temperature reduced the viscosity of the solution and thus offered less resistance to the movement of ions to form current. The surface morphology is influenced by the current density, the concentration of nickel salts in the bath and the type of current applied. The increase in current density improved the amount of weight of electro-deposited, thus increased the thickness of nickel deposit. 


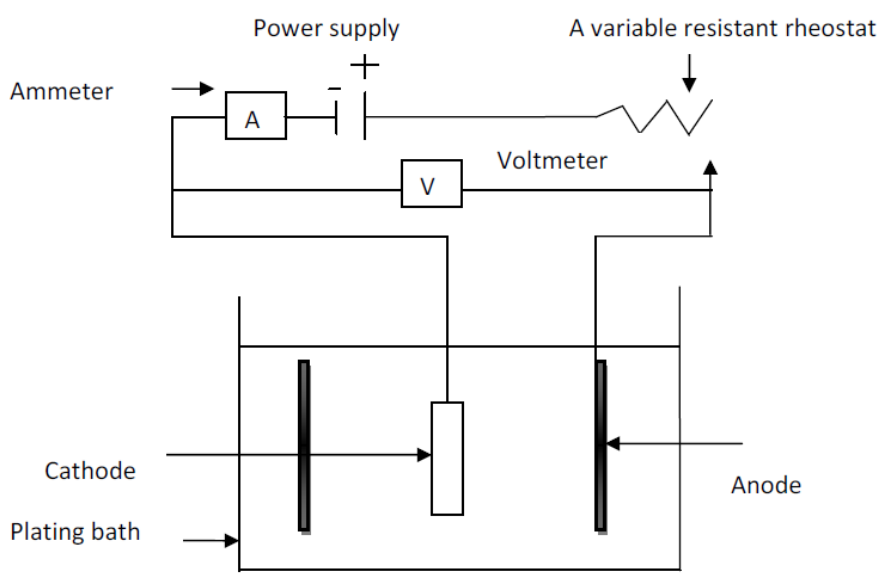

Figure 1. Scheme of the electrochemical plating of Ni.

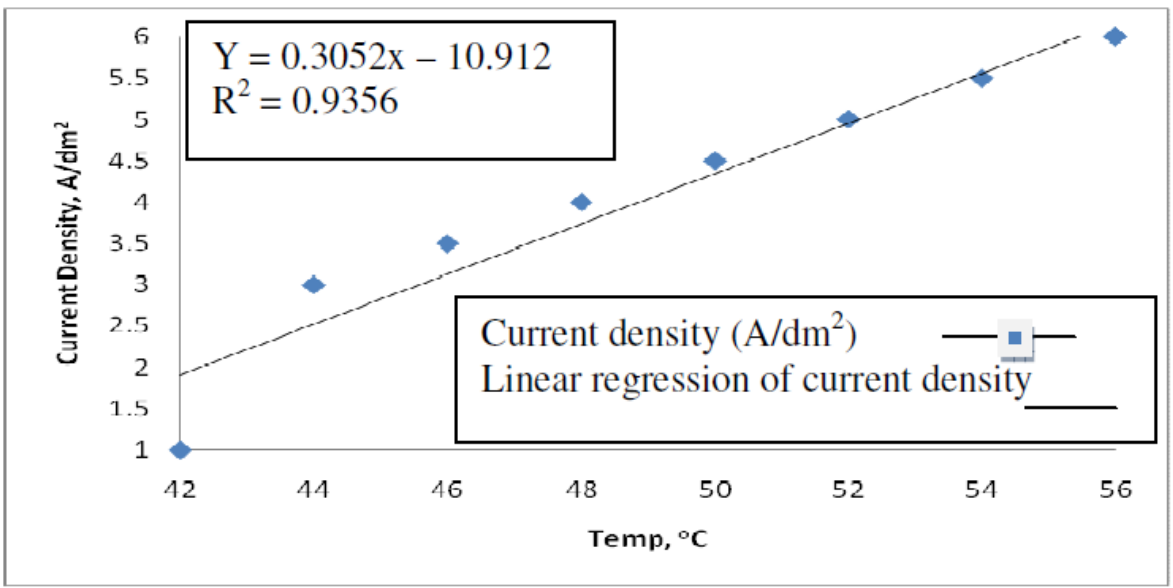

Figure 2. The effect of temperature on current density in ionic solutions of nickel.

Tables 3 and 4 give the temperature effect on the specimens and the operational parameters used in the experiment. Fig. 3 also shows that there is even a clearer correlation between the temperature and the voltage, as the temperature increases with increasing voltage, with a coefficient of fit of $\approx 99 \%$. Different result was obtained at different plating time. It was observed that at 18 minutes, the best plating was obtained. At 27 minutes, the surface of the metal was not attractive, which indicates that the time was too long for plating.

Table 3. Effect of temperature on specimens.

\begin{tabular}{|c|c|l|}
\hline Temperature $/\left({ }^{\circ} \mathrm{C}\right)$ & Current density $/\left(\mathrm{A} / \mathrm{dm}^{2}\right)$ & Brigthness \\
\hline 42 & 1 & Dull brigth \\
\hline 44 & 3 & Dull brigth \\
\hline 46 & 3.5 & Brigth \\
\hline 48 & 4 & Brigth \\
\hline 50 & 4.5 & Brigther \\
\hline 52 & 5 & Brigther \\
\hline 54 & 5.5 & Brigther \\
\hline 56 & 6 & Brigthest \\
\hline 56 & 6 & Brigthest \\
\hline
\end{tabular}




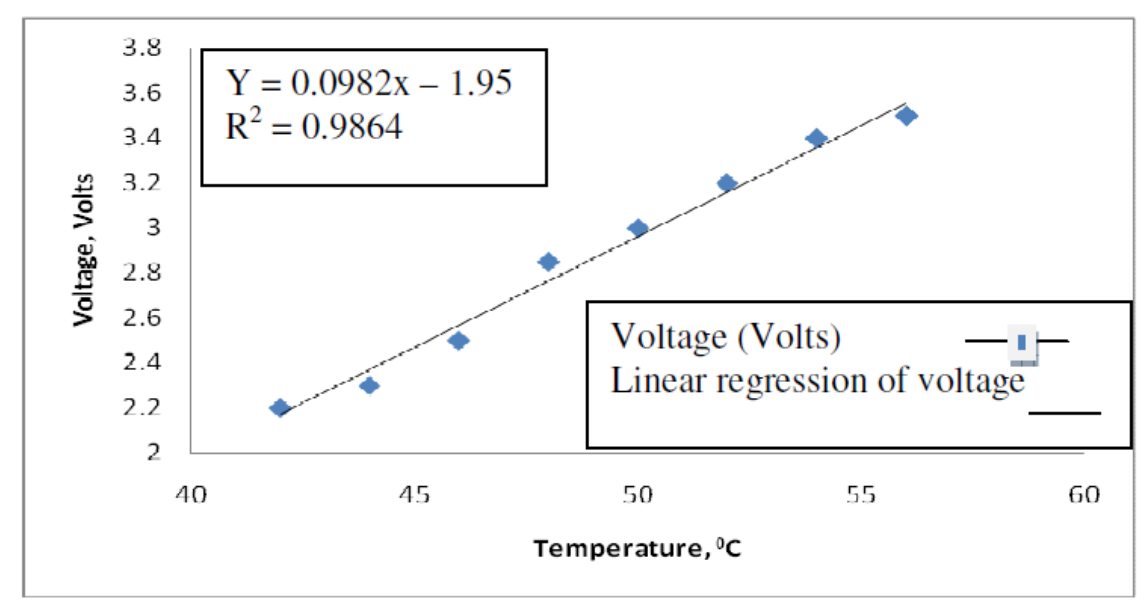

Figure 3. Voltage vs. temperature.

Table 4. Operational parameters.

\begin{tabular}{|c|c|c|c|}
\hline Temperature / $\left({ }^{\mathbf{0}} \mathbf{C}\right)$ & Voltage / (Volts) & Time / (Mins) & Current density / (A/dm $\left.{ }^{2}\right)$ \\
\hline 42 & 2.0 & 27 & 1 \\
\hline 44 & 2.3 & 25 & 3 \\
\hline 46 & 2.5 & 24 & 3.5 \\
\hline 48 & 2.8 & 23 & 4 \\
\hline 50 & 3 & 20 & 4.5 \\
\hline 52 & 3.2 & 22 & 5 \\
\hline 54 & 3.4 & 19 & 5.5 \\
\hline 56 & 3.5 & 18 & 6 \\
\hline 56 & 3.5 & 18 & 6 \\
\hline
\end{tabular}

Fig. 4 and 5 show that the thickness of the deposit depends on the plating time and on the current density. The best time of electroplating bright nickel depends on plating temperature, composition and current density. Time has direct effect on coating thickness, as shown in Fig 6; as expected, the thickness increases nonlinearly, though with increase in time.

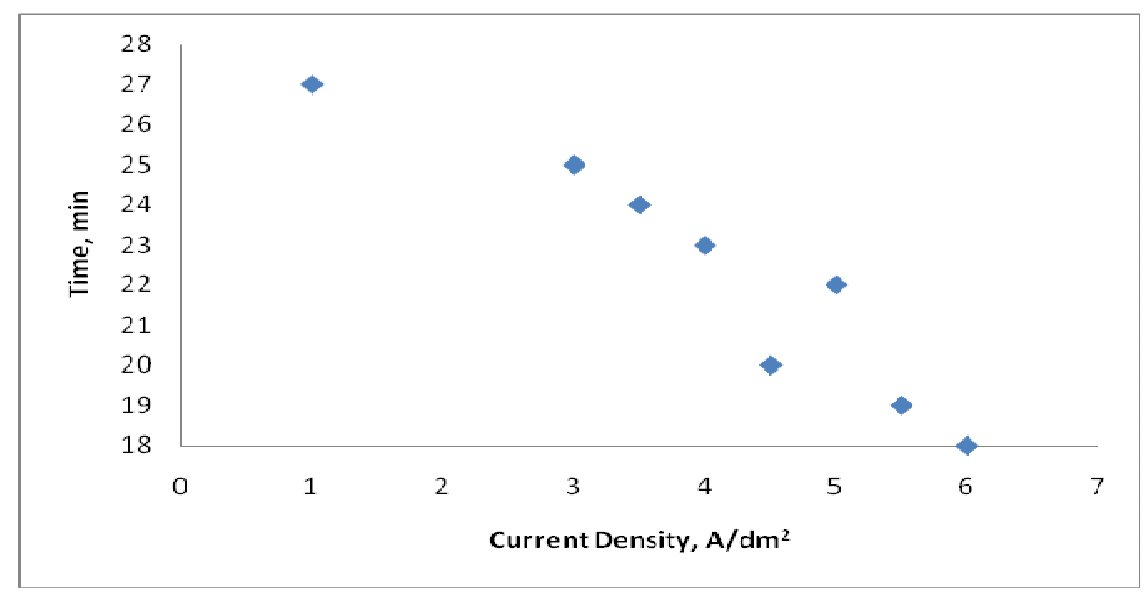

Figure 4. Current density vs. time. 


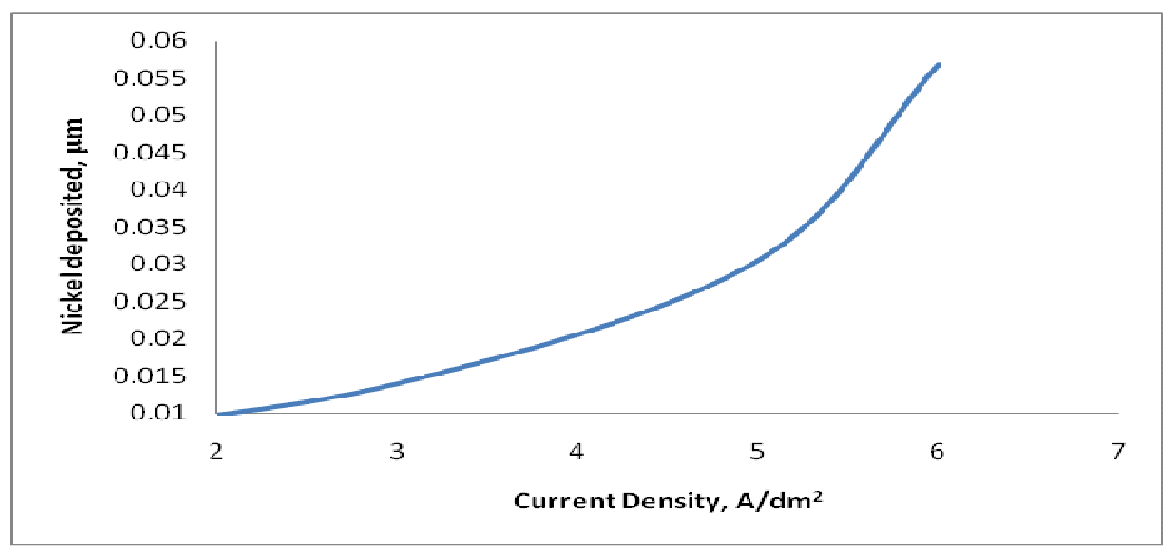

Figure 5. Deposit thickness vs. current density.

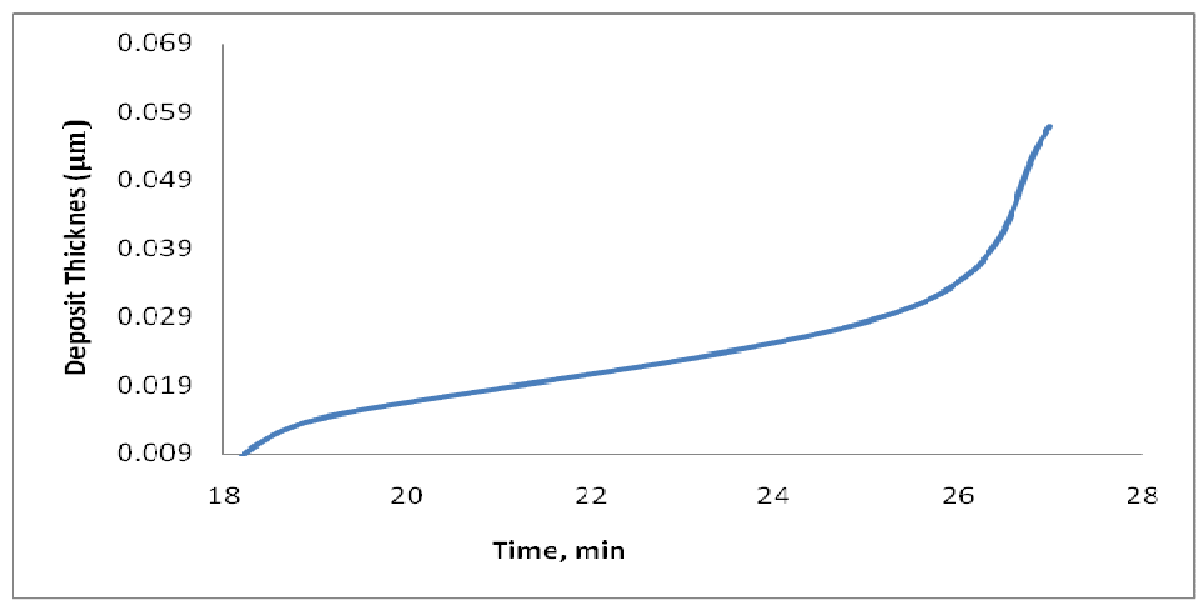

Figure 6. The time dependent thickness for nickel deposit.

\section{Conclusion}

This work demonstrated the influence of operating parameters on brigth nickel plating. It is clear that the factors that influence the cathode film and thereby the quality of the deposit are: plating temperature, current density, $\mathrm{pH}$, voltage and plating time. These factors are all inter-related; if a variable such as current density is altered considerably without other factors being altered at the same time, adverse effects on the deposit may be observed. It was found that in bright nickel plating, the concentration of nickel salt has an effect on the weight of nickel deposited on the cathode. It was also observed that when the temperature was higher, the specimen withstood high peak current density of $6 \mathrm{~A} / \mathrm{dm}^{2}$, without the formation of burnt deposit, as shown in Table 3 and Fig. 2. It was observed that the thickness increases with increases in time. Deposits from the sulfamate nickel plating baths have very fine grain and as a result, the deposits are very smooth and brighter in appearance at the temperature of $56{ }^{\circ} \mathrm{C}$. The cleaner the surface of the material, the brighter is the material after plating. The regression line was used to determine the flexibility of the variables (temperature, voltage and current density), which shows that there is a clear relationship between the temperature and current density and there is also a clear relationship between the temperature and the voltage. The $\mathrm{pH}$ ranges from 4 to 
4.5, which ensured that the metal particles remained in the solution and deposited evenly on the materials.

\section{References}

1. Q. Xu, A. Telukdarie, H.H. Lou, Y. Huang, Ind. Eng. Chem. Res. 44 (2005) 2156. 10.1021/ie0495067

2. E. Binkauskene, Rus. J. Appl. Chem. $75 \quad$ (2002) 852. 10.1023/A:1020395520503

3. R.D. Davis, Nickel, Cobalt and their Alloys. ASM International Handbook Committe. U.S.A., 2000. p.106-107.

4. A.O. Gezerman, B.D. Corbacioglu, Int. J. Chem. 2 (2010) 124.

5. L. Chao-qun, L. Xin-hai, W. Zhi-xin, G. Hua-Jun, Transition Nonferrous Metals Soc. China 17 (2007) 1300.

6. D. Golodnitsky, N.V. Gudin, G.A. Volyanuk, Journal of the Electrochemical Society 147 (2000) 4156. 10.1149/1.1394034

7. P. Spacek, M. AngeManier, A. El Moudni, Int. J. System Sci. 30 (1999) 759. 10.1080/002077299292065

8. V.I. Karavaev, I.L. Korobova, V. Litovka Yu, Rus. J. Appl. Chem. 79 (2006) 1840. 10.1134/S1070427206110152

9. J. Zhang, J. Mater. Processing Tech. 123 (2002) 329. 10.1016/S09240136(02)00012-2

10. E. Kukharenka, M.M. Farooqui, L. Grigore, M. Kraft, N. Hollinshead, J. Micromech. Microeng. 13 (2003) S67. 10.1088/0960-1317/13/4/311

11. Y. Kaneko, Y. Hiwatari, K. Ohara, F. Asa, Molecular Simulation 32 (2006) 1227. 10.1080/08927020601067540

12. M. Vidal, J.M. Amigo, R. Bro, M. Ostra, C. Ubide, Analytical Method 2 (2010) 86. 10.1039/b9ay00158a

13. S. Lambert, Circuit World 32 (2006) 36. 10.1108/03056120610683612

14. R. Ghanem, H. Farag, Y. Etlaweel, M.E. Ossman, Int. J. Chem. Eng. Research 1 (2009) 135. 